\title{
Immunization with recombinant class 1 outer- membrane protein from Neisseria meningitidis: influence of liposomes and adjuvants on antibody avidity, recognition of native protein and the induction of a bactericidal immune response against meningococci
}

\author{
Myron Christodoulides, Joy L. Brooks, Elizabeth Rattue \\ and John E. Heckels
}

Author for correspondence: Myron Christodoulides. Tel: +44 1703 796974. Fax: +44 1703774316. e-mail: mc4@soton.ac.uk

Molecular Microbiology Group, University of Southampton Medical School, Southampton General Hospital, Southampton SO16 6YD, UK
The porA gene from Neisseria meningitidis was cloned into the PRSETA vector and recombinant class 1 outer-membrane protein expressed at high levels in Escherichia coli. The protein was readily purified by affinity chromatography on a $\mathrm{Ni}^{2+}$ matrix and used for immunization of mice with conventional $\mathrm{Al}(\mathrm{OH})_{3}$ adjuvant, with experimental adjuvants which have the potential for human use, and with liposomes. The resulting sera were analysed for the magnitude, subclass distribution and antigenic specificity of the immune response. In addition, surface plasmon resonance (SPR) was used to quantify antibody avidity by analysis of the kinetics of binding to native class 1 protein. Immunization with conventional and experimental adjuvants induced antibodies of low avidity that did not recognize native class 1 protein. In contrast, immunization with recombinant protein in liposomes induced antibodies of high avidity which recognized native class 1 protein, as measured by their ability to label meningococcal cells in immunofluorescence assays and to inhibit the binding of a protective mAb. These properties were associated with the presence in sera of high levels of antibodies with the ability to induce complement-mediated killing of meningococci. These data show that liposomes containing recombinant class 1 protein represent a potential basis of future vaccines, of defined composition, designed for the prevention of group B meningococcal infections.

Keywords: Neisseria meningitidis, liposome, adjuvant, antibody avidity, vaccine

\section{INTRODUCTION}

A continuing need exists for an effective vaccine for the prevention of life-threatening meningitis and septicaemia caused by Neisseria meningitidis. The current vaccines, which are based on the group-specific capsular

\footnotetext{
Abbreviations: DS, dialysis-sonication; HRP, horseradish peroxidase; IF, immunofluorescence; MPLA, monophosphoryl lipid A; MTP-PE, muramyl tripeptide-phosphatidylethanolamine; OM, outer membrane; OMV, outer-membrane vesicle; SEC, size-exclusion chromatography; SPR, surface plasmon resonance.
}

polysaccharides, provide adults with only short-term protection against serogroups $\mathrm{A}$ and $\mathrm{C}$, and are ineffective in infants. In addition, these vaccines afford no protection against serogroup B strains, the predominant cause of infection in most temperate countries. Since purified group B polysaccharide shows structural similarity with human glycoproteins, especially in the developing foetal brain, and is non-immunogenic in humans, concerns have been raised over its inclusion in meningococcal vaccines (Finne et al., 1983). Therefore, new experimental vaccines based on outer-membrane proteins are currently being investigated. 
During the past decade, experimental vaccines against group B meningococcal disease have been developed, based on outer-membrane protein vesicles, and have undergone phase III trials in humans (Bjune et al., 1991; Demoraes et al., 1992; Boslego et al., 1995; Perkins et al., 1998). Although these vaccines induced limited protection in adults (Boslego et al., 1995; Carbonare et al., 1995), the immune responses were invariably of short duration (Rosenquist et al., 1995) and did not protect children under two years of age (Demoraes et al., 1992; Milagres et al., 1994), who are at greatest risk of infection. In addition, because of the heterogeneous nature of outer-membrane vesicle (OMV) vaccines, the induced humoral immune responses were characterized by the presence of antibodies against a number of outermembrane antigens; only a proportion of these antibodies were protective (Rosenquist et al., 1995).

Several antigens associated with the outer membrane (OM) have been shown to induce an immune response following invasive disease or vaccination with experimental OMV vaccines. The class 1 porin appears to be particularly effective in generating a bactericidal immune response following infection (Idanpaan-Heikkila et al., 1995), and the bactericidal activity in sera from humans immunized with experimental vaccines appears largely to be associated with the production of anti-class 1 protein antibodies (Wedege \& Froholm, 1986; Milagres et al., 1994; Rosenquist et al., 1995; van der Voort et al., 1996). Therefore, the class 1 porin is regarded as the most promising candidate for inclusion in new vaccines, and is the basis of a multivalent OMV vaccine (van der Ley et al., 1995) which has undergone phase I trials in adult human volunteers (Peeters et al., 1996).

The class 1 protein is a major component of the $\mathrm{OM}$ and functions as a cationic porin. It is expressed by most meningococcal strains (Tsai et al., 1981), and has an apparent molecular mass of $41-42 \mathrm{kDa}$. The cloning and sequencing of the por $A$ genes, which encode the class 1 porin (Barlow et al., 1989), has permitted structural and antigenic studies which have led to a model for the organization of the protein within the outer membrane. The predicted structure is of 16 amphipathic $\beta$-strands traversing the $\mathrm{OM}$ and generating eight surface-exposed hydrophilic loops (van der Ley et al., 1991). Comparison of the porA gene and predicted amino acid sequences of the class 1 protein from a number of strains reveals that antigenic variation is confined largely to two discrete regions designated VR1 and VR2, which are located in the longest surfaceexposed loops 1 and 4, respectively (McGuinness et al., 1993). This restricted antigenic diversity provides the basis for the sero-subtyping classification of meningococci. In addition, these variable regions contain epitopes which are also recognized by bactericidal and protective murine mAbs (McGuinness et al., 1993) and, most importantly, by sera from humans vaccinated with experimental OMV vaccines (van der Voort et al., 1996).

Studies on the vaccine potential of class 1 porin would be facilitated by the production of native pure protein, free from other components of the meningococcal outer membrane. In preliminary studies, the entire por $A$ gene has been cloned and high-level expression of the class 1 protein in Escherichia coli achieved using the pGEMEX-1 vector system (Ward et al., 1996). However, this system produced a recombinant fusion protein which was not optimal for immunization studies, due to the presence of a $29 \mathrm{kDa}$ leader sequence derived from the bacteriophage T7 gene 10 capsid protein. Although the class 1 protein has also been cloned and expressed in the Gram-positive organism Bacillus subtilis (Nurminen et al., 1992; Muttilainen et al., 1995b), improved expression systems are still required for the production of recombinant meningococcal protein(s) in E. coli.

In this study, we describe high-level expression of the class 1 protein in $E$. coli, without the presence of a large $\mathrm{N}$-terminal leader protein and in a form which can be readily purified. The resulting recombinant protein was used in studies with mice to determine the effect of vaccine formulations, compatible with human immunization, on the specificity and avidity of the antibodies induced and their ability to recognize the native protein on meningococcal cells and induce complementmediated killing of meningococci.

\section{METHODS}

Bacterial strains, plasmids and growth conditions. Neisseria meningitidis strain MC50 (C:NT:P1.21,16) and the subtype $\mathrm{P} 1.7,16$ reference strain $\mathrm{H} 44 / 76$ (B:15:P1.7,16) have been described previously (Christodoulides et al., 1993). Strain MC114 (B:2a:P1.2), originally designated M986, was obtained from Dr J. Poolman, RIVM, The Netherlands. All strains were grown on protease-peptone agar at $37^{\circ} \mathrm{C}$ for $18 \mathrm{~h}$ in an atmosphere of $5 \%(\mathrm{v} / \mathrm{v}) \mathrm{CO}_{2}$. OMs were prepared by extraction of whole cells with lithium acetate as described by Tinsley \& Heckels (1986) and OMV was produced by extraction of the outer membranes with $1 \%(\mathrm{w} / \mathrm{v})$ sodium deoxycholate in $1 \mathrm{mM}$ Tris/ $\mathrm{HCl}, \mathrm{pH} \mathrm{8.5,10} \mathrm{mM}$ EDTA (Frasch \& Robbins, 1978).

The pPORA104 plasmid containing the porA gene encoding the class 1 protein from meningococcal strain MC50 has been described previously (White et al., 1990). The pRSET expression vector was obtained from Promega. Recombinant plasmids were transformed into E. coli strain JM109(DE3) (Promega) and grown at $37^{\circ} \mathrm{C}$ in LB medium (Difco) containing $200 \mu \mathrm{g}$ ampicillin $\mathrm{ml}^{-1}$, and on LB-ampicillin plates (Ward et al., 1996).

Monoclonal antibodies. mAbs used were SM300, which specifically recognizes the P1.16 subtype-specific epitope on meningococcal class 1 protein (McGuinness et al., 1993), and SM301, which exhibits identical antigenic specificity (unpublished observations).

Cloning and expression of class 1 protein in E. coli. A $1.6 \mathrm{~kb}$ $X$ hol-HindIII fragment of the porA gene from strain MC50 $(P 1.21,16)$, which encoded the three $N$-terminal residues of the 19 amino acid signal sequence together with the mature class 1 protein, was excised from pPORA104 (White et al., 1990). The porA gene fragment was directionally ligated into the pRSETA vector, which includes DNA inserts enencoding a small $\mathrm{N}$-terminal fusion peptide of approximately 34 amino acids containing an initiation codon, six histidine residues that 
function as a nickel-binding domain in the translated class 1 protein, a transcript-stabilizing sequence from gene 10 of phage T7 and the enterokinase cleavage recognition sequence. The resulting plasmid, pPORA110, was transformed into $E$. coli JM109(DE3), which contains a chromosome-encoded T7 RNA polymerase gene under the control of the lacUV5 promoter (White et al., 1990).

E. coli JM109(DE3) containing plasmid pPORA110 was grown in LB broth containing ampicillin $\left(200 \mu \mathrm{g} \mathrm{m}^{-1}\right)$ to midexponential phase. Expression of the plasmid-encoded class 1 protein was induced by the addition of IPTG to a final concentration of $1 \mathrm{mM}$. After $5 \mathrm{~h}$ incubation at $37^{\circ} \mathrm{C}$, the cells were harvested by centrifugation at $10000 \mathrm{~g}$ for $1 \mathrm{~h}$ at $4^{\circ} \mathrm{C}$.

Purification of recombinant class 1 protein under denaturing conditions. Cells of $E$. coli expressing recombinant class 1 protein were lysed by the addition of $20 \mathrm{mM}$ sodium phosphate buffer, $\mathrm{pH} 8.0$, containing $0.5 \mathrm{M} \mathrm{NaCl}$ and $6 \mathrm{M}$ guanidine hydrochloride (lysis buffer; $5 \mathrm{ml}$ per $\mathrm{g}$ wet weight of cells) with stirring at room temperature for $1 \mathrm{~h}$. After centrifugation, the supernatant solution (1) was removed, and the cell debris was resuspended in an equal volume of lysis buffer and subjected to sonication (MSE Soniprep 150 sonicator). The remaining insoluble material was removed by centrifugation for $30 \mathrm{~min}$ at $10000 \mathrm{~g}$ at $4{ }^{\circ} \mathrm{C}$, and the supernatant solution (2) was stored at $-20^{\circ} \mathrm{C}$ until use. Recombinant class 1 protein from the combined supernatants ( 1 and 2) was purified by affinity chromatography. A column $(0.5 \times 15 \mathrm{~cm})$ of Ni-NTA resin (Qiagen) was equilibrated with lysis buffer and the cell lysate was pumped onto the column at a flow rate of $15 \mathrm{ml} \mathrm{h}^{-1}$. The column was washed with lysis buffer, then eluted sequentially with $20 \mathrm{mM}$ sodium phosphate buffer containing $0.5 \mathrm{M} \mathrm{NaCl}$ and $8 \mathrm{M}$ urea at decreasing $\mathrm{pH}$ values of $8 \cdot 0,6 \cdot 3$, 5.9 and 4.5 . Fractions $(3 \mathrm{ml})$ were collected, and the $\mathrm{pH}$ adjusted immediately to $7 \cdot 0$. The presence of eluted recombinant class 1 protein was determined by absorbance at $280 \mathrm{~nm}$, protein assay (BCA, Pierce) and SDS-PAGE. Fractions from the $\mathrm{pH} 5.9$ eluate which contained the recombinant class 1 protein were pooled, the protein was precipitated by the addition of ethanol $\left(80 \%, \mathrm{v} / \mathrm{v}\right.$, final) and after $18 \mathrm{~h}$ at $4{ }^{\circ} \mathrm{C}$ the precipitate was collected by centrifugation at $13000 \mathrm{~g}$ for $10 \mathrm{~min}$, and dried briefly under vacuum. The protein was stored at $-20^{\circ} \mathrm{C}$ with desiccant until used.

SDSPAGE and Western immunoblotting. SDS-PAGE was performed using a $10-25 \%(\mathrm{w} / \mathrm{v})$ linear gradient gel, proteins were transferred to nitrocellulose and immunological reactivity was detected using anti-mouse Ig-alkaline phosphatase conjugate as described previously (Christodoulides et al., 1993).

Incorporation of recombinant class 1 protein into artificial liposomes. Liposomes were prepared using a dialysis-sonication (DS) method with L- $\alpha$-phosphatidylcholine and cholesterol (Sigma) as previously described (Ward et al., 1996). Briefly, lipid and cholesterol (7:2 molar ratio, $20 \mathrm{mg}$ total) were dissolved in chloroform (at $10 \mathrm{mg} \mathrm{m}^{-1}$ ) in a roundbottomed flask and the solvent was removed under vacuum with rotation to produce an even lipid film. The recombinant protein ( $1 \mathrm{mg}$ ) was dissolved in $0.1 \%(\mathrm{w} / \mathrm{v})$ SDS with sonication in a $37^{\circ} \mathrm{C}$ water bath, and octyl- $\beta$-glucoside (OG) in $100 \mathrm{mM}$ HEPES buffer, $\mathrm{pH} 7 \cdot 2$, was added to give a final concentration of $10 \mathrm{mM}$ HEPES and $10 \%$ (w/v) OG. This detergent/protein solution was then used to solubilize the shell-dried lipid, and unilamellar membrane vesicles were produced by dialysis followed by sonication (DS liposomes). Liposomes containing recombinant protein were also prepared using size-exclusion chromatography (SEC) according to the method of Muttilainen et al. (1995b). Briefly, L- $\alpha$ phosphatidylcholine $(20 \mathrm{mg})$ and OG $(100 \mathrm{mg})$ were dissolved in chloroform/methanol $(2: 1)$ and used to produce a lipid film. Recombinant protein (1 mg) in $100 \mathrm{mM}$ Tris $/ \mathrm{HCl}$, $\mathrm{pH} 8.0$, containing $\mathrm{KCl}(100 \mathrm{mM})$, OG $(2 \%, \mathrm{w} / \mathrm{v})$ and SDS $(0.4 \%, \mathrm{w} / \mathrm{v})$ was used to dissolve the lipid film, and the mixture was passed through a column $(1.5 \times 30 \mathrm{~cm})$ of Sephadex G50. Fractions containing protein and lipid were pooled and stored at $-20^{\circ} \mathrm{C}$ until used (SEC liposomes).

The production of small unilamellar vesicles containing the surface-exposed recombinant class 1 protein VR2 epitope which reacts with the P1.16 subtype-specific mAb SM300, was monitored by immunoelectron microscopy as described previously (Ward et al., 1996). DS liposomes were also prepared incorporating the adjuvant monophosphoryl lipid A (MPLA; Ribi Immunochem), at an adjuvant:protein ratio of $1: 1(\mathrm{w} / \mathrm{w})$, as described previously (Ward et al., 1996). Liposomes incorporating a lipophilic adjuvant muramyl tripeptide-phosphatidylethanolamine (MTP-PE; a gift from Ciba-Geigy, Basel, Switzerland) were also prepared in a similar manner.

\section{Immunization of animals}

Preparation of protein/adjuvant mixtures. The recombinant class 1 protein was dissolved in $0.1 \%$ SDS to give a protein concentration of $5 \mathrm{mg} \mathrm{m}^{-1}$; this solution was diluted into saline to give a final concentration of $200-400 \mu \mathrm{g} \mathrm{m}^{-1}$. Three different protein/adjuvant mixtures were prepared. (1) The protein solution $\left(200 \mu \mathrm{g} \mathrm{m}^{-1}\right)$ was mixed with an equal volume of $\mathrm{Al}(\mathrm{OH})_{3}$ suspension (2\% Alhydrogel; Superfos) and allowed to adsorb overnight at $4{ }^{\circ} \mathrm{C}$. (2) The protein solution $\left(400 \mu \mathrm{g} \mathrm{ml}^{-1}\right)$ was emulsified with Ribi adjuvant (Ribi Immunochem) to give a final concentration of $20 \mu \mathrm{g}$ protein per $100 \mu \mathrm{l}$ emulsion, according to the manufacturer's instructions. (3) An emulsion was prepared containing $0.4 \%$ Tween $80,5 \%$ block copolymer L121 (BASF) and $10 \%$ squalane (Eastman Kodak) in saline (Byars \& Allison, 1987), and mixed with an equal volume of recombinant class 1 protein solution $\left(200 \mu \mathrm{g} \mathrm{ml}^{-1}\right)$.

Immunization. Balb/C $\left(\mathrm{H}-2^{\mathrm{d}}\right)$ mice at $6-7$ weeks of age were used for immunizations, with pre-bleeds taken before primary immunization. Groups of five mice of approximately equal weight were each immunized subcutaneously with $20 \mu \mathrm{g}$ recombinant class 1 protein in the above preparations on days 0,21 and 42 . Mice were terminally bled on day 52 and sera were stored at $-20^{\circ} \mathrm{C}$.

\section{Detection of immune response}

ELISA. Flat-bottomed polystyrene microtitre plates were coated overnight at $37^{\circ} \mathrm{C}$ with either recombinant protein or OM $\left(1 \mu \mathrm{g} \mathrm{ml}^{-1}\right)$ in $0.05 \mathrm{M}$ sodium carbonate buffer, $\mathrm{pH} 9 \cdot 6$. Antibody binding was detected using the appropriate HRP conjugate (Zymed) with 3,3',5,5'-tetramethylbenzidine and $\mathrm{H}_{2} \mathrm{O}_{2}$ as enzyme substrate. Absorbance was measured at $450 \mathrm{~nm}$ and the ELISA titre, extrapolated from the linear portion of the serum titration curve, was taken as the reciprocal dilution which gave an absorbance of 0.1 units $\mathrm{h}^{-1}$ (Christodoulides et al., 1993).

Subclass-specific ELISA. Antibody subclass was determined by OM ELISA using rat monoclonal anti-mouse $\operatorname{IgG1}, 2 \mathrm{a}, 2 \mathrm{~b}$ and IgM HRP conjugates (Zymed). For IgG3, a biotin-conjugated rat monoclonal anti-mouse IgG3 antibody (Pharmingen) and HRP-streptavidin (Zymed) were used. All conjugates were used at a dilution of 1:1000 and no cross-reactivity was observed between conjugates of defined specificity and Ig of other subclasses from a panel of purified mouse immuno- 
globulins (Zymed). To quantify the levels of antibody in murine antisera, standard curves were constructed using ${ }^{125} \mathrm{I}-$ labelled pure Ig subclasses of defined specific activity [c.p.m. ( $\mu \mathrm{g}$ protein $)^{-1}$.

Competition ELISA assays. Antisera were tested for their ability to compete with, and inhibit, the binding of $\mathrm{mAb} \mathrm{SM} 301$, which recognizes the subtype $\mathrm{P} 1.16$ epitope, to OMs from strain MC50 (P1.21,16). The mAb was biotinylated by oxidation with sodium periodate (Sigma) followed by reaction with biotin hydrazide (Calbiochem) (Hermanson et al., 1992). Serial dilutions of pooled antisera were mixed with the concentration of biotinylated $\mathrm{mAb}$ SM301 that gave $50 \%$ of the maximum absorbance in ELISA, and incubated in microtitre plates coated with MC50 OM for $1 \mathrm{~h}$ at $37^{\circ} \mathrm{C}$. After washing, binding of the biotinylated antibody was detected using HRP-streptavidin conjugate (Zymed; 1:2000).

Immunofluorescence (IF). The reactivity of antisera with native class 1 protein present on the surface of meningococcal cells was detected by IF. Suspensions of $N$. meningitidis strains MC50, H44/76 and MC114 were prepared in PBS, placed on microscope slides and allowed to air-dry. The dried suspensions were fixed in acetone $(100 \%)$ for $10 \mathrm{~min}$ at room temperature, washed in PBS then blocked with PBS containing BSA $(1 \%, w / v)$ for $15 \mathrm{~min}$. Serial dilutions of pooled murine test antisera were reacted with fixed organisms for $1 \mathrm{~h}$ at $25^{\circ} \mathrm{C}$ with gentle mixing, and after washing, bound antibody was detected by reactivity with anti-mouse Ig-FITC conjugate (Dako) in PBS (1:100), using a fluorescence microscope (Leitz).

Bactericidal assays. The bactericidal activity of antisera was determined with strain MC50 essentially as previously described, using $5 \%$ guinea pig serum as a source of exogenous complement (Christodoulides et al., 1993). As a positive control for the bactericidal assays, murine antisera raised to purified OMs (P1.16) were used. The statistical significance of any bactericidal activity observed for each pooled antiserum compared to the corresponding pre-immune serum was determined using $F$ - and $t$-tests as described previously (Christodoulides et al., 1993).

Kinetic analysis of antibody reactivity with OMs by surface plasmon resonance (SPR). Interactions of antisera raised to recombinant class 1 protein with $\mathrm{P} 1.16$ OMs was studied in real time by the technique of SPR (Jonsson et al., 1991) using a BIAcore 2000 instrument (BIAcore AB). The surface of hydrophobic sensor chip HPA (BIAcore AB) was washed with octyl- $\beta$-glucoside ( $40 \mathrm{mM}$ solution) according to the manufacturer's instructions and followed immediately with $O M$ from strain MC50 ( $2 \mu \mathrm{g}$ protein $\mathrm{ml}^{-1}$ solution in PBS) at a flow rate of $5 \mu \mathrm{min}^{-1}$ for $3 \mathrm{~h}$. The chip surface was then washed with PBS $\left(100 \mu \mathrm{min}^{-1}\right)$ to remove any multiple membrane layers. Adsorption of OM was shown by the reactivity of a P1.16 subtype-specific $\mathrm{mAb}$ and the lack of reactivity of normal mouse serum and a heterologous $\mathrm{mAb}$ (directed against the chlamydial major OM protein). Pooled test antisera were diluted $(1: 100)$ in PBS and injected in discrete pulses $(35 \mu \mathrm{l})$ over membrane-adsorbed surfaces at a continuous flow rate $\left(5 \mu \mathrm{min}^{-1}\right)$ at $25^{\circ} \mathrm{C}$. Dissociation of bound antisera was observed for $15 \mathrm{~min}$, and the chip surfaces were regenerated with $50 \mathrm{mM}$ phosphoric acid between samples. Data points from the early part of the dissociation phase were fitted to the manufacturer's model equations for calculations of dissociation rate constants $\left(k_{d}, s^{-1}\right)$ for each polyclonal antiserum. Comparison of the binding avidities of antibodies in different sera was performed by measurement of the reciprocal $\left(1 / k_{\mathrm{d}}\right)$ of the dissociation rate constants (Van Cott et al., 1994).

\section{RESULTS}

Cloning of the meningococcal porA gene in $E$. coli using the PRSETA vector: expression and purification of recombinant class 1 protein

In preliminary studies (Ward et al., 1996), the class 1 porin from strain MC50 had been expressed in E. coli as a fusion with the bacteriophage T7 gene 10 capsid protein, which contributed a large leader sequence of approximately $29 \mathrm{kDa}$ N-terminal to the meningococcal protein. Only low levels of bactericidal antibodies could be raised to this fusion protein when incorporated into liposomes, and it appeared likely that the large leader sequence had a profound effect on the conformation of the class 1 protein. In this study, the pRSET vector was used to express class 1 protein in E. coli, without the large leader sequence. After lysis of the $E$. coli cells in $6 \mathrm{M}$ guanidine hydrochloride, the recombinant class 1 protein was readily purified by affinity chromatography on a $\mathrm{Ni}^{2+}$ column. From a typical batch culture ( 2 litres), the approximate yield of purified protein was $60 \mathrm{mg}$ (from $9.4 \mathrm{~g}$ wet weight $E$. coli cells). SDS-PAGE revealed a single homogeneous protein band of approximately $45 \mathrm{kDa}$, which reacted with $\mathrm{mAb}$ SM300, specific for the subtype P1.16 epitope of the class 1 protein. No lipopolysaccharide was detected by SDS-PAGE and silver staining.

\section{Humoral immune response to recombinant class 1 protein}

The purified protein was used to immunize mice with Ribi adjuvant and pluronic block copolymer emulsions, both of which have the potential for human use. To attempt to present the protein in its native conformation for immunization experiments, the recombinant class 1 porin was incorporated into liposomes prepared both by DS and SEC. Immunoelectron microscopy confirmed the presence of an immunoreactive P1.16 epitope on the liposome surface. As a control, the protein was adsorbed to $\mathrm{Al}(\mathrm{OH})_{3}$, the standard adjuvant routinely licensed for human use.

The influence of vaccine formulation on the humoral immune response was studied initially by the reactivity of antisera with the purified recombinant protein in ELISA. Immunization with the protein in the Ribi and pluronic emulsions induced a strong immune response to the recombinant protein, with titres $>1 \times 10^{6}$ (Table $1)$. The responses using these adjuvants were significantly greater $(P>0.05)$ than those elicited by the recombinant protein incorporated into liposomes prepared by either method. In an attempt to increase the immunogenicity of the recombinant protein in liposomes, DS liposomes were also prepared with the inclusion of additional immunomodulators, MPLA or MTP-PE. However, the inclusion of these adjuvants did not significantly increase the immune response to the recombinant protein (Table 1 ).

A different pattern of reactivity was observed when antisera were tested against the native protein in 
Table 1. Reactivity of antisera obtained following immunization with recombinant class 1 protein formulated with adjuvants or liposomes

Pre- and post-immunization sera were tested by ELISA against recombinant protein and OMs from the homologous strain MC50 (P1.21,16), and strains H44/76 (P1.7,16) and MC114 (P1.2). Data are from groups of five mice and are presented as the reciprocal mean ELISA titre $\left(\times 10^{-3}\right)$; ND, not done.

\begin{tabular}{|c|c|c|c|c|c|c|c|c|c|}
\hline \multirow[t]{4}{*}{ Immunogen } & \multirow[t]{4}{*}{ Adjuvant formulation } & \multicolumn{8}{|c|}{$10^{3} \times$ Reciprocal mean ELISA titres for antisera tested against: } \\
\hline & & \multirow{2}{*}{\multicolumn{2}{|c|}{$\begin{array}{l}\text { Homologous } \\
\text { recombinant } \\
\text { class } 1 \text { protein }\end{array}$}} & \multicolumn{6}{|c|}{ OMs of strain: } \\
\hline & & & & \multicolumn{2}{|c|}{$\begin{array}{c}\text { MC50 } \\
(\mathrm{P} 1.21,16)\end{array}$} & \multicolumn{2}{|c|}{$\begin{array}{c}\text { H44/76 } \\
(\mathbf{P} 1.7,16)\end{array}$} & \multicolumn{2}{|c|}{$\begin{array}{c}\text { MC114 } \\
\text { (P1.2) }\end{array}$} \\
\hline & & Pre & Post & Pre & Post & Pre & Post & Pre & Post \\
\hline Class 1 protein & $\mathrm{Al}(\mathrm{OH})_{3}$ & 1 & 1513 & 1 & 54 & 1 & 3 & 1 & 1 \\
\hline Class 1 protein & Ribi & 1 & 1451 & 1 & 82 & 1 & 10 & 1 & 4 \\
\hline Class 1 protein & Pluronic & 2 & 2325 & 1 & 176 & 2 & 154 & 1 & 17 \\
\hline Class 1 protein & DS liposomes & 1 & 311 & 1 & 614 & 1 & 869 & 1 & 3 \\
\hline Class 1 protein & SEC liposomes & 1 & 250 & 1 & 250 & 1 & 250 & 1 & 10 \\
\hline Class 1 protein & DS liposomes + MPLA & 1 & 520 & 1 & 22 & 1 & 109 & 1 & 9 \\
\hline Class 1 protein & DS liposomes + MTP-PE & 2 & 249 & 1 & 21 & 1 & 82 & 1 & 12 \\
\hline OMV (MC50) & $\mathrm{Al}(\mathrm{OH})_{3}$ & ND & ND & 1 & 998 & 1 & 1831 & 1 & 123 \\
\hline- & Empty liposomes & 2 & 1 & 1 & 1 & 1 & 4 & 1 & 5 \\
\hline- & Normal mouse serum & 1 & 1 & 1 & 1 & 1 & 5 & 1 & 7 \\
\hline
\end{tabular}

Table 2. Subclass-specific response to class 1 protein in OMs following immunization by recombinant class 1 protein formulated with adjuvants or liposomes

Concentrations of antibody subclasses in murine antisera were determined by ELISA using enzyme conjugates of rat monoclonal antibodies specific for mouse Ig subclasses. Data are presented as the mean antibody isotype [ $\mu \mathrm{g}$ (ml serum) ${ }^{-1}$ ] from groups of five individual mice. A concentration of $<0 \cdot 1 \mu \mathrm{g} \mathrm{m}^{-1}$ denotes below the minimum detectable concentration.

\begin{tabular}{|c|c|c|c|c|c|c|}
\hline \multirow[t]{2}{*}{ Immunogen } & \multirow[t]{2}{*}{ Adjuvant formulation } & \multicolumn{5}{|c|}{ Mean concn of antibody isotype [ $\left.\mu \mathrm{g}(\mathrm{ml} \text { serum })^{-1}\right]$} \\
\hline & & IgG1 & IgG2a & $\operatorname{IgG} 2 \mathrm{~b}$ & IgG3 & IgM \\
\hline Class 1 protein & $\mathrm{Al}(\mathrm{OH})_{3}$ & 6 & $<0.1$ & $<0 \cdot 1$ & $<0 \cdot 1$ & 3 \\
\hline Class 1 protein & Ribi & 1 & 3 & $<0 \cdot 1$ & 4 & 19 \\
\hline Class 1 protein & Pluronic & 6 & 6 & 4 & 1 & 11 \\
\hline Class 1 protein & DS liposomes & 237 & 180 & 13 & 19 & 6 \\
\hline Class 1 protein & SEC liposomes & 64 & 97 & 8 & 4 & 5 \\
\hline Class 1 protein & DS liposomes + MPLA & 3 & $<0.1$ & $<0 \cdot 1$ & $<0 \cdot 1$ & $<0 \cdot 1$ \\
\hline Class 1 protein & SEC liposomes + MTP-PE & 3 & $<0 \cdot 1$ & $<0 \cdot 1$ & $<0 \cdot 1$ & $<0 \cdot 1$ \\
\hline OMV (MC50) & $\mathrm{Al}(\mathrm{OH})_{3}$ & 212 & 255 & 191 & 25 & 10 \\
\hline- & Empty liposomes & $<0 \cdot 1$ & $<0 \cdot 1$ & $<0 \cdot 1$ & $<0 \cdot 1$ & $<0 \cdot 1$ \\
\hline- & Normal mouse serum & $<0 \cdot 1$ & $<0 \cdot 1$ & $<0 \cdot 1$ & $<0.1$ & $<0 \cdot 1$ \\
\hline
\end{tabular}

homologous OMs of strain MC50 (P1.21,16). Antisera raised with Ribi, pluronic copolymer or $\mathrm{Al}(\mathrm{OH})_{3}$ showed significantly lower (approx. 20-fold) reactivity than observed with the recombinant protein. Within this group of adjuvants, the antisera raised using pluronic copolymer showed greater reactivity with OMs than did antisera raised with either the Ribi adjuvant or $\mathrm{Al}(\mathrm{OH})_{3}$. However, the highest response to the homologous OM was shown by antisera raised to the recombinant protein in DS or SEC liposomes. These showed a reactivity with OMs which was similar to that observed with the purified protein and significantly greater $(P>0.05)$ than the reactivities of antisera raised with the other adjuvants (Table 1). In contrast, inclusion of the immunomodulators MPLA or MTP-PE into liposomes significantly reduced the ability of the resulting antisera to react with the homologous OMs (Table 1). The humoral immune responses to the recombinant protein incor- 
Table 3. Kinetic analysis of antibody reactivity with meningococcal OM using SPR

Meningococcal OMs from the homologous strain MC50 (P1.21,16) were adsorbed to the surface of an HPA biosensor chip. Pooled test antisera were reacted with adsorbed $O M$, and dissociation rate constants $\left(k_{\mathrm{d}}, \mathrm{s}^{-1}\right)$ were determined from the resulting sensorgrams after subtraction of normal mouse serum background. Reciprocal dissociation rate constant $\left(k_{\mathrm{d}}, \mathrm{s}^{-1}\right)$ values were used as measures of antiserum avidity. NDA, no detectable association.

\begin{tabular}{|c|c|c|c|}
\hline Immunogen & Adjuvant formulation & $\begin{array}{c}10^{5} \times \text { Dissociation } \\
\text { constant }( \pm S E)\end{array}$ & $\begin{array}{c}\text { Reciprocal } \\
\text { dissociation constant }\end{array}$ \\
\hline Class 1 protein & $\mathrm{Al}(\mathrm{OH})_{3}$ & $169 \pm 6$ & 590 \\
\hline Class 1 protein & Ribi & $187 \pm 1$ & 530 \\
\hline Class 1 protein & Pluronic & $132 \pm 4$ & 760 \\
\hline Class 1 protein & DS liposomes & $2 \cdot 8 \pm 0 \cdot 4$ & 36000 \\
\hline Class 1 protein & SEC liposomes & $3.4 \pm 0.8$ & 29000 \\
\hline Class 1 protein & DS liposomes + MPLA & NDA & - \\
\hline Class 1 protein & DS liposomes + MTP-PE & NDA & - \\
\hline OMV (MC50) & $\mathrm{Al}(\mathrm{OH})_{3}$ & $52( \pm 0 \cdot 4)$ & 1900 \\
\hline
\end{tabular}

porated into DS and SEC liposomes or prepared with the pluronic adjuvant were subtype-specific, as demonstrated by similar reactivity between the homologous OMs and those of strain $\mathrm{H} 44 / 76(\mathrm{P} 1.7,16)$, which shares the common P1.16 subtype epitope, but little reactivity with heterologous outer membranes from strain MC114 (P1.2) (Table 1).

\section{Subclass-specific response to class 1 protein in OMs}

The subclass-specific response to class 1 protein in homologous OMs was determined by ELISA using antimouse Ig isotype-specific conjugates. The antibody subclasses detected in antisera raised to the recombinant protein incorporated into liposomes were predominantly IgG1 (35-52\%) and IgG2a $(40-54 \%)$. These levels of IgG1 and IgG2a antibodies were similar to those induced by immunization with OMV, although the latter also induced a significantly greater proportion of IgG2b antibodies (Table 2). Because low levels of anti-OM antibodies were induced by immunization with liposomes incorporating additional immunomodulators, or by the $\mathrm{Al}(\mathrm{OH})_{3}$, pluronic emulsion and Ribi preparation (Table 1), subclass levels in these antisera were very low or not detected (Table 2).

\section{Kinetic analysis of antibody binding by SPR}

The avidity of the antibody recognition of class 1 protein in OMs was analysed by real-time monitoring of antibody binding and dissociation using the technique of $\mathrm{SPR}$. The recombinant class 1 protein in liposomes elicited antisera with the highest avidity, showing reciprocal dissociation rate constants of $3-4 \times 10^{4} \mathrm{~s}$ (Table 3), which were approximately 50 -fold greater than observed with the low avidity antisera elicited by immunization with $\mathrm{Al}(\mathrm{OH})_{3}$, and the Ribi or pluronic emulsions $\left(5-8 \times 10^{2} \mathrm{~s}\right)$. The avidity of binding of the anti-liposome sera was also significantly greater than that determined for antisera raised to the OMV vaccine $\left(1.9 \times 10^{3} \mathrm{~s}\right)$. Antisera raised to liposomes incorporating

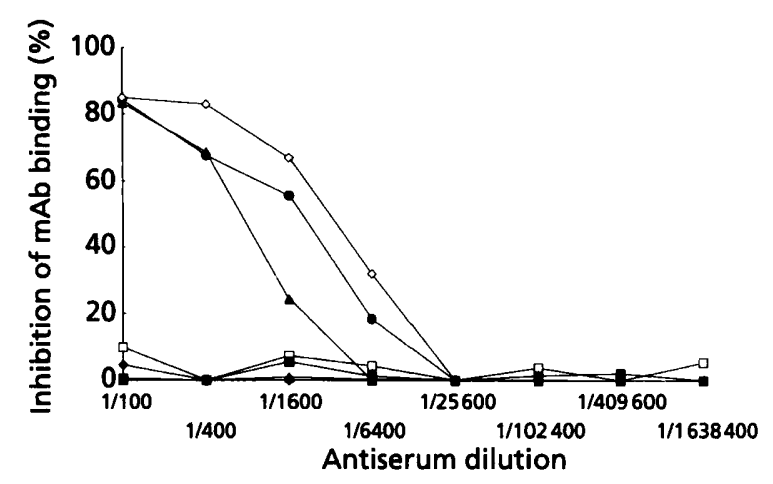

Fig. 1. Recognition of the protective subtype-specific epitope on class 1 protein in OMs. Pooled antisera were tested for their ability to compete with, and inhibit, the binding of mAb SM301 to the class 1 protein in OMs. Serial dilutions of murine antisera were mixed with biotinylated mAb SM301, and the mixture was reacted in an ELISA with OMs from the homologous strain MC50 (P1.21,16). Data are presented as the percentage inhibition of binding of mAb SM301 measured at each dilution point. The data presented represent mean values from duplicates carried out in a single experiment and are representative of experiments carried out on at least six separate occasions. Inhibition curves are shown for antisera raised to recombinant class 1 protein with: $\mathrm{Al}(\mathrm{OH})_{3}(\mathrm{O})$, Ribi $(\triangle)$, Pluronic $(\square)$, DS liposomes (O), SEC liposomes $(\Delta)$, DS liposomes + MPLA $(\square)$, DS liposomes + MTP-PE $(\bullet)$, MC50 OMV $(\diamond)$, empty liposomes $(X)$. Those symbols not visible are on the baseline of the figure.

the immunomodulators MPLA or MTP-PE showed no significant association with OMs adsorbed to the sensor chip, and consequently no dissociation rate constants could be determined.

\section{Recognition of the protective subtype-specific epitope on the class 1 protein in OMs}

To investigate the ability of induced antibodies to recognize the protective P1.16 epitope within the VR2 region at the apex of surface-exposed loop 4 of the class 
Table 4. Antibody recognition of native class 1 protein on meningococcal cells by IF

Pooled antisera raised to recombinant class 1 protein with adjuvants or in liposomes were reacted with meningococcal cells. Bound antibody was detected by reactivity with FITC-labelled anti-mouse Ig conjugate followed by fluorescence microscopy. As controls, antisera raised to OMV of strain MC50 or empty liposomes were used. +, Strong positive labelling of meningococcal cells; - , no labelling.

\begin{tabular}{|clccc|}
\hline Immunogen & Adjuvant formulation & \multicolumn{2}{c|}{ IF on meningococcal cells of strain: } \\
\cline { 3 - 5 } & & MC50 & H44/76 & $\begin{array}{c}\text { MC114 } \\
\text { (P1.2) }\end{array}$ \\
\hline Class 1 protein & $\mathrm{Al}(\mathrm{OH})_{3}$ & $(\mathbf{P 1 . 2 1 , 1 6 )}$ & $(\mathbf{P 1 . 1 7 , 1 6 )}$ & - \\
Class 1 protein & Ribi & - & - & - \\
Class 1 protein & Pluronic & - & - & - \\
Class 1 protein & DS liposomes & + & + & - \\
Class 1 protein & SEC liposomes & + & + & - \\
Class 1 protein & DS liposomes +MPLA & - & - & - \\
Class 1 protein & DS liposomes + MTP-PE & - & - & - \\
OMV (MC50) & Al(OH $)_{3}$ & + & + & - \\
- & Empty liposomes & - & - & - \\
- & Normal mouse serum & - & - & - \\
\hline
\end{tabular}

1 protein, ELISA inhibition experiments were carried out with a mAb (SM301) which specifically recognizes the epitope. Antisera raised to the recombinant protein in liposomes effectively inhibited the binding of the subtype-specific $\mathrm{mAb}$, with $50 \%$ inhibitory dilution values of $1: 1000-1: 2110$ (Fig. 1). No significant inhibition was shown by antisera raised with any of the other adjuvants or with liposomes incorporating additional immunomodulators, even at the lowest dilution of antiserum tested $(1: 10)$. In control experiments, antisera raised against OMV demonstrated a $50 \%$ inhibitory value of approximately $1: 3200$.

\section{Antibody recognition of native class 1 protein on meningococcal cells by IF}

The ability of antisera to recognize native class 1 protein on meningococcal cells was determined by IF (Table 4). Only antisera raised to the recombinant class 1 protein in liposomes showed strong binding to meningococcal cells of the homologous strain MC50 (P1.21,16). This reactivity was subtype-specific, since antibody binding was also observed to meningococcal cells of strain H44/76 (P1.7,16), which shares the common P1.16 epitope, but not to the heterologous strain MC114 (P1.2). No binding to meningococcal cells was observed with antisera raised with any of the other adjuvants or with liposomes incorporating additional immunomodulators. Control experiments with antisera raised against OMVs showed similar binding to that observed with the liposomes containing recombinant protein alone.

\section{Bactericidal activity of antisera}

Antisera raised against the recombinant class 1 protein were tested for their ability to promote in vitro complement-mediated killing of the homologous menin-

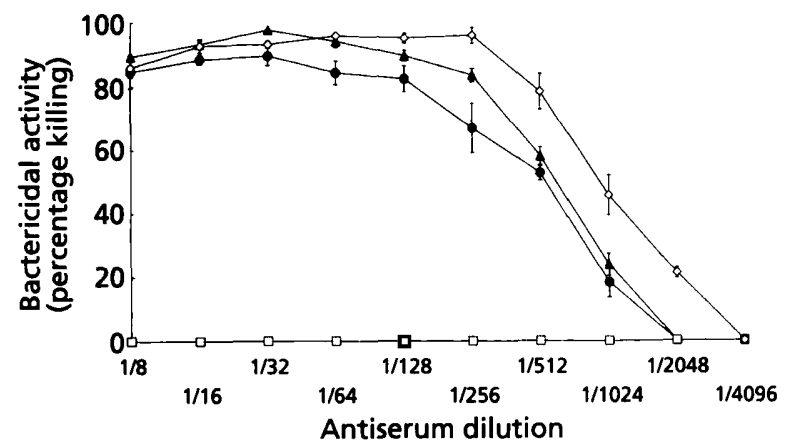

Fig. 2. Bactericidal effect of murine antisera raised against recombinant class 1 protein with adjuvants or in liposomes. Pooled sera were tested for their ability to promote complement-mediated killing of the homologous strain MC50 $(P 1.21,16)$. Results are expressed as the percentage of bacteria killed by antiserum in the presence of complement, compared to pre-immune serum and complement. Bactericidal activity is shown for antisera raised to DS liposomes (O), SEC liposomes (A). MC50 OMV $(\diamond)$. All other antisera $(\square)$ showed no bactericidal activity. For each immunogen, sera from individual mice $(n=5)$ were pooled and tested, assays were carried out in triplicate, and individual experiments were performed on at least three separate occasions. Error bars represent the standard deviation of the observed mean killing in a single experiment.

gococcal strain MC50. Antisera to the recombinant protein in DS and SEC liposomes demonstrated significant killing of meningococci, with bactericidal titres of approximately 1:512 (Fig. 2) for both preparations. This was similar to the bactericidal activity of antisera raised against the OMV vaccine prepared from the same strain (titre of approximately $1: 1024$ ). None of the other antisera, raised with other adjuvants or with liposomes incorporating additional immunomodulators, was able 
to promote complement-mediated killing of meningococci.

\section{DISCUSSION}

Human trials with OMV vaccines have demonstrated the potential of outer-membrane proteins for inducing protective immune responses to group B meningococci (Bjune et al., 1991; Demoraes et al., 1992; Boslego et al., 1995). A large-scale phase III trial of an OMV vaccine in Norwegian teenagers demonstrated an efficacy of $57 \%$ (Bjune et al., 1991). However, because of the complex composition of OMV vaccines, the identity of the antigens which induce protective immunity is not fully known. Detailed analysis of serum from individuals immunized with the Norwegian vaccine led to the conclusion that antibodies to the class 1 and Opc proteins made the most important contributions to bactericidal activity against the vaccine strain (Rosenqvist et al., 1995). Although this study also showed a contribution by antibodies directed against other antigens, these are as yet uncharacterized and the class 1 and Opc proteins remain the only antigens which have been associated with the production of a protective effect in human vaccine trials. The Opc protein, which shows limited variation between strains, is therefore a potential vaccine candidate but it is not expressed by many disease isolates and it may be down-regulated during invasive disease (Achtman et al., 1991). In contrast, the class 1 protein, which is expressed by most (but not all) strains, is responsible for sero-subtype differences between strains (Frasch et al., 1985). This heterogeneity has led to the development of a multivalent OMV vaccine, which contains six different subtypes covering over $80 \%$ of the subtypes encountered in many countries, and in which class 1 proteins represent over $90 \%$ of the total vaccine protein (Claassen et al., 1996; van der Voort et al., 1996). Thus, at present, the class 1 protein appears to be the most promising of the OMPs for inclusion in new meningococcal vaccines.

Studies on the vaccine potential of class 1 protein, and other meningococcal OM proteins, would be facilitated by a convenient means of production of protein free from other meningococcal OM antigens. In this study, the porA gene was cloned into the pRSETA vector and recombinant protein was expressed to high levels in $E$. coli. Purification was readily achieved by affinity chromatography on a $\mathrm{Ni}^{2+}$ matrix via the specific interaction of a (His) ${ }_{6}$ sequence at the $\mathrm{N}$-terminus of the cloned protein. A major advantage of this expression system is that the recombinant protein does not contain the large leader sequence $\mathrm{N}$-terminal to the class 1 protein, present in the previous studies (Ward et al., 1996).

\section{Effect of adjuvants on immune response to class 1 protein}

The adjuvant effect required for immune response to proteins within OMV vaccines is provided by their vesicular structure, by the presence of residual traces of lipooligosaccharides and by adsorption to $\mathrm{Al}(\mathrm{OH})_{3}$. To be able to induce an immune response to proteins which are produced free from OMVs is likely to require the addition of a more effective adjuvant than $\mathrm{Al}(\mathrm{OH})_{3}$, which is the only adjuvant licensed for routine use with human vaccines. The recombinant class 1 protein was therefore used for immunization studies in mice with $\mathrm{Al}(\mathrm{OH})_{3}$ and compared with two experimental adjuvants, namely Ribi emulsion (Rudbach et al., 1995) and a pluronic block copolymer emulsion (Hunter et al., 1991), both of which have been used in humans for phase I/II trials of vaccines (Quan et al., 1997; Hoffman et al., 1994; Schultz et al., 1995). All three preparations induced comparable immune responses to the recombinant protein, as measured by ELISA, although the pluronic copolymer emulsion was much more effective in inducing antibodies able to recognize native class 1 protein in OMs. However, antisera raised with all three adjuvants were of low avidity for OMs and did not recognize native class 1 protein on the surface of meningococci, as determined by IF. In particular, they all failed to induce complement-mediated killing of meningococci. It is likely that the recombinant protein in these preparations adopted a conformation which was not capable of inducing antibodies which recognize the protective epitopes exposed on the surface of meningococcal cells.

\section{Immune response to class 1 protein in liposomes}

In an attempt to induce antibodies directed against native conformational epitopes, the recombinant protein was incorporated into liposomes. Liposomes are closed, concentric, phospholipid bilayers which have been used extensively by the pharmaceutical industry for targeted drug delivery to humans (Gregoriadis, 1995), and recently in phase I trials of experimental human vaccines against malaria (Fries et al., 1992), influenza and hepatitis A (Cryz et al., 1996). The advantages of using liposomes as vaccines are that they are biodegradable, non-toxic and non-immunogenic, and are capable of inducing both humoral and cellmediated immunity with a large variety of antigens (Gregoriadis, 1995). This immunoadjuvant activity, combined with the similarity of liposomes to biological membranes, provides a rationale for the preparation of experimental human vaccines which present membrane proteins in a native conformation. Liposomes containing purified PI porin from gonococci were originally shown to elicit antibodies which react with isolated OMs (Jiskoot et al., 1986) and subsequently to induce a bactericidal immune response (Wetzler et al., 1988). Recently, recombinant class 1 protein produced in $B$. subtilis has been shown to induce bactericidal antibodies directed against meningococci (Muttilainen et al., 1995a). In the current study, the recombinant class 1 protein was incorporated into liposomes, prepared both by DS using a mixture of phospholipid and cholesterol (Ward et al., 1996) and by SEC using phospholipid alone (Muttilainen et al., 1995b). Both methods produced vesicles which induced essentially similar humoral 
immune responses with respect to magnitude, avidity, subclass distribution and antigenic specificity.

Antisera produced by immunization with the recombinant protein in liposomes demonstrated a subtype-specific reaction with class 1 protein in isolated OMs. Previous studies have suggested that such a subtype-specific response may be correlated, at least to some degree, with the induction of antibodies capable of recognizing the native protein (Ward et al., 1996; Muttilainen et al., 1995b). In the present study, the ability of the antibodies to recognize the native class 1 protein on the surface of meningococci was demonstrated by IF detection of antibodies bound to meningococcal cells, and by their ability to inhibit the binding of a $\mathrm{mAb}$ which recognizes a protective epitope located at the apex of surface-exposed loop 4 . These activities were comparable to those observed with antibodies raised against OMVs. In contrast, the antisera raised with $\mathrm{Al}(\mathrm{OH})_{3}, \mathrm{Ribi}$ and pluronic adjuvants did not recognize native class 1 protein.

Another important attribute of the immune response against meningococci is likely to be the avidity of binding of the induced antibodies to exposed surface antigens. In this study, SPR was used to analyse the kinetics of antibody binding to OMs adsorbed to the hydrophobic surface of biosensor chips. Using this technique, avidity constants can be calculated from the association and dissociation of purified $\mathrm{mAbs}$ of known concentration (Karlsson et al., 1991). Although such analyses are not possible for polyclonal serum, because of their polydisperse nature and the unknown concentration of individual antibody species, comparisons of avidity can still be made by examining dissociation rate constants, which are inversely proportional to avidity and independent of concentration under saturating conditions (Van Cott et al., 1994). Antisera raised against recombinant protein in liposomes demonstrated high avidity of binding, with reciprocal dissociation rate constants approximately 50 -fold greater than those obtained with the adjuvant preparations. Although SPR analyses also indicated that the liposomes induced more avid antisera than immunization with OMV, this is presumably due to the fact that the OMV preparation contains a variety of proteins which induce antibodies of varying specificity. In contrast, the liposome preparations induce antibodies to a single protein only, and these antibodies bind specifically to one antigen present in the OM.

In an attempt to enhance further the magnitude and avidity of the immune response, liposomes were also prepared with the inclusion of additional adjuvants, MPLA or MTP-PE, which were chosen for their compatibility with liposomes and for their potential use in human immunization (Verma et al., 1992; Braun et al., 1995). However, incorporation of these adjuvants into liposomes had a deleterious effect on antibody binding to native protein in OMs, despite high levels of antibodies reactive with denatured protein, suggesting that they interfered with the native conformation of the porin in the lipid bilayer, as opposed to a failure of the adjuvant itself. This failure to induce biologically functional antibodies therefore demonstrates a lack of native conformation of the class 1 protein in these preparations.

\section{Functional activity of the immune response}

Immunization of mice with the recombinant protein in liposomes also induced a broad distribution of antibody isotypes, similar to that seen with the OMV vaccine. This property of the antigen may be particularly important since a broad distribution of isotypes, with different immune effector functions, is likely to be required for protection against infection. The generally accepted correlate of in vivo protection, which can be measured in vitro, is the ability of sera to promote complement-mediated killing of meningococci (Goldschneider et al., 1969). The antisera raised to the recombinant class 1 protein in liposomes promoted high levels of bactericidal activity against meningococci which were comparable to the levels observed following immunization with the OMV vaccine. In contrast, the sera raised with the other adjuvants failed to kill meningococci. Comparison between the antisera raised with pluronic adjuvant and the SEC liposomes showed similar reactivity with class 1 protein in OM ELISA. However, the non-bactericidal antibodies induced by pluronic adjuvant demonstrated a low reciprocal dissociation constant, whereas the bactericidal antibodies induced by the liposomes had a high reciprocal dissociation constant value. This finding is similar to that seen with the HIV-1 virus where the antibody dissociation rate and not the association rate or ELISA titre was found to be predictive of the neutralizing capacity of $\mathrm{mAbs}$ directed against the gp120 envelope glycoprotein (Van Cott et al., 1994). The results obtained in the current study confirm that SPR analysis of the binding kinetics of polyclonal sera can also be used to provide biologically relevant reciprocal dissociation constant measurements.

Although bactericidal activity is generally accepted as the most important marker for protection against meningococcal infection, such assays are time-consuming, and the results are difficult to reproduce and are subject to intra-laboratory variation. In the current study, bactericidal activity was associated with the presence in sera of high-avidity antibodies, as demonstrated by SPR, with the ability both to inhibit binding of a protective $\mathrm{mAb}$ and to bind to meningococcal cells in IF assays. Such properties indicate the presence of antibodies which effectively recognize the native class 1 protein on the surface of meningococcal cells. The SPR assay in particular provides a rapid, reproducible and quantifiable assay for the screening of large numbers of sera raised by immunization with experimental vaccines containing meningococcal OM antigens.

The system used in the current study has provided a convenient method for expression of recombinant class 1 protein in $E$. coli. This has wider implications for the 
study of other OM proteins, particularly those which may be present in the meningococcal $O M$ at low levels or which may be subject to environmental regulation of expression, since it permits high-level expression of recombinant proteins which can readily be purified by affinity chromatography for vaccine studies. In particular, the present work shows that recombinant class 1 protein, when incorporated into liposomes, induces a subtype-specific, potentially protective immune response against meningococci. It is likely that an effective vaccine would incorporate a limited number of class 1 proteins of different subtypes, to cover a wide range of meningococcal strains (Claassen et al., 1996). Such liposomes, of defined composition, therefore represent strong candidates for the basis of future vaccines, designed for the prevention of group B meningococcal infections.

\section{ACKNOWLEDGEMENTS}

This work was supported by the National Meningitis Trust and by a Medical Research Council Project Grant.

\section{REFERENCES}

Achtman, M., Wall, R. A., Bopp, M., Kusecek, B., Morelli, G., Saken, E. \& Hassanking, M. (1991). Variation in class 5 protein expression by serogroup A meningococci during a meningitis epidemic. J Infect Dis 164, 375-382.

Barlow, A. K., Heckels, J. E. \& Clarke, I. N. (1989). The class 1 outer membrane protein of Neisseria meningitidis: gene sequence and structural and immunological similarities to gonococcal porins. Mol Microbiol 3, 131-139.

Bjune, G., Hoiby, E. A., Gronnesby, J. K. \& 14 other authors (1991). Effect of outer membrane vesicle vaccine against group $B$ meningococcal disease in Norway. Lancet 338, 1093-1096.

Boslego, J., Garcia, J., Cruz, C. \& 11 other authors (1995). Efficacy, safety, and immunogenicity of a meningococcal group B (15-P1.3) outer-membrane protein vaccine in Iquique, Chile. Vaccine 13, 821-829.

Braun, D. G., van Hoogevest, P. \& Schumann, G. (1995). Muramyl tripeptide-phosphatidylethanolamine: a muramyl dipeptide derivative with lipophilic properties. In The Theory and Practical Application of Adjuvants, pp. 213-238. Edited by D. E. S. Stewart-Tull. Chichester: Wiley.

Byars, N. E. \& Allison, A. C. (1987). Adjuvant formulation for use in vaccines to elicit both cell-mediated and humoral immunity. Vaccine 5, 223-228.

Carbonare, S. B., Arslanian, C., Silva, M. M., Farhat, C. K. \& Carneirosampaio, M. S. (1995). The antimeningococcal vaccine VA-MENGOC-BC induced poor serum and salivary antibodyresponse in young Brazilian children. Pediatr Infect Dis J 14, 797-803.

Christodoulides, M., McGuinness, B. T. \& Heckels, J. E. (1993). Immunisation with synthetic peptides containing epitopes of the class 1 outer membrane protein of Neisseria meningitidis: production of bactericidal antibodies on immunisation with a cyclic peptide. J Gen Microbiol 139, 1729-1738.

Claassen, I., Meylis, J., van der Ley, P. \& 9 other authors (1996). Production, characterization and control of a Neisseria meningitidis hexavalent class 1 outer membrane protein containing vesicle vaccine. Vaccine 14, 1001-1008.

Cryz, S. J., Que, J. U. \& Gluck, R. (1996). A virosome vaccine antigen delivery system does not stimulate an antiphospholipid antibody response in humans. Vaccine 14, 1381-1383.

Demoraes, J. C., Perkins, B. A., Camargo, M. C. C. \& 9 other authors (1992). Protective efficacy of a serogroup B meningococcal vaccine in Sao Paulo, Brazil. Lancet 340, 1074-1078.

Finne, J., Leinonen, M. \& Makela, P. H. (1983). Antigenic similarities between brain components and bacteria causing meningitis: implications for vaccine development and pathogenesis. Lancet ii, 355-357.

Frasch, C. E. \& Robbins, J. D. (1978). Protection against group B meningococcal disease. III. Immunogenicity of serotype 2 vaccines and specificity of protection in a guinea pig model. J Exp Med 147, 629-644.

Frasch, C. E., Zollinger, W. D. \& Poolman, J. T. (1985). Serotype antigens of Neisseria meningitidis and a proposed scheme for designation of serotypes. Rev Infect Dis 7, 504-510.

Fries, L. F., Gordon, D. M., Richards, R. L., Egan, J. E., Hollingdale, M. R., Gross, M., Silverman, C. \& Alving, C. R. (1992). Liposomal malaria vaccine in humans - a safe and potent adjuvant strategy. Proc Natl Acad Sci USA 89, 358-362.

Goldschneider, I., Gotschlich, E. C. \& Artenstein, M. S. (1969). Human immunity to the meningococcus. I. The role of humoral antibodies. J Exp Med 129, 1307-1326.

Gregoriadis, G. (1995). Liposomes as immunological adjuvants. In The Theory and Practical Application of Adjuvants, pp. 145-169. Edited by D. E. S. Stewart-Tull. Chichester: Wiley.

Hermanson, G. T., Mallia, A. K. \& Smith, P. K. (1992). Immobilised Affinity Ligand Techniques. London: Academic Press.

Hoffman, S. L., Edelman, R., Bryan, J. P. \& 13 other authors. (1994). Safety, immunogenicity and efficacy of a malaria sporozoite vaccine administered with monophosphoryl lipid A, cellwall skeleton of mycobacteria, and squalane as adjuvant. $A m \mathrm{~J}$ Trop Med Hyg 51, 603-612.

Hunter, R., Olsen, M. \& Buynitzky, S. (1991). Adjuvant activity of nonionic block copolymers. 4. Effect of molecular weight and formulation on titer and isotype of antibody. Vaccine 9, 250-256.

Idanpaan-Heikkila, I., Hoiby, E. A., Chattopadhyay, P., Airaksinen, U., Michaelsen, T. M. \& Wedege, E. (1995). Antibodies to meningococcal class 1 outer-membrane protein and its variable regions in patients with systemic meningococcal disease. $J$ Med Microbiol 43, 335-343.

Jiskoot, W., Teerlink, T., Van Hoof, M. M. M., Bartels, K., Kanhai, V., Crommelin, D. J. \& Beuvery, E. C. (1986). Immunogenic activity of gonococcal protein $I$ in mice with three different lipoidal adjuvants delivered in liposomes and in complexes. Infect Immun 54, 333-338.

Jonsson, U., Fagerstam, L., Ivarsson, B. \& 13 other authors (1991). Real-time biospecific interaction analysis using surface-plasmon resonance and a sensor chip technology. Biotechniques 11, 620-627.

Karlsson, R., Michaelsson, A. \& Mattsson, L. (1991). Kinetic analysis of monoclonal antibody-antigen interactions with a new biosensor based analytical system. J Immunol Methods 145, 229-240.

van der Ley, P., Heckels, J. E., Virji, M., Hoogerhout, P. \& Poolman, J. T. (1991). Topology of outer membrane porins in pathogenic Neisseria spp. Infect Immun 59, 2963-2971.

van der Ley, P., van der Biezen, J. \& Poolman, J. T. (1995). Construction of Neisseria meningitidis strains carrying multiple chromosomal copies of the porA gene for use in the production of a multivalent outer membrane vesicle vaccine. Vaccine 13, 401-407. 
McGuinness, B. T., Lambden, P. R. \& Heckels, J. E. (1993). Class 1 outer membrane protein of Neisseria meningitidis: epitope analysis of the antigenic diversity between strains, implications for subtype definition and molecular epidemiology. Mol Microbiol 7, 505-514.

Milagres, L. G., Ramos, S. R., Sacchi, C. T., Melles, C. E. A., Vieira, V. S. D., Sato, H., Brito, G. S., Moraes, J. C. \& Frasch, C. E. (1994). Immune response of Brazilian children to a Neisseria meningitidis serogroup $B$ outer membrane protein vaccine: comparison with efficacy. Infect Immun 62, 4419-4424.

Muttilainen, S., Butcher, S. J., Runeberg, K., Nurminen, M., Idanpaan-Heikkila, I., Wahlstrom, E. \& Sarvas, M. (1995a). Heterologous production of the $\mathrm{P} 1$ porin of Neisseria meningitidis in Bacillus subtilis: the effect of an N-terminal extension on the presentation of native-like epitopes. Microb Pathog 18, 365-371.

Muttilainen, S., Idanpaan-Heikkila, I., Wahlstrom, E., Nurminen, M., Makela, P. H. \& Sarvas, M. (1995b). The Neisseria meningitidis outer membrane protein P1 produced in Bacillus subtilis and reconstituted into phospholipid vesicles elicits antibodies to native P1 epitopes. Microb Pathog 18, 423-436.

Nurminen, M., Butcher, S., Idanpaan-Heikkila, I., Wahlstrom, E., Muttilainen, S., Runeberg-Nyman, K., Sarvas, M. \& Makela, P. H. (1992). The class 1 outer membrane protein of Neisseria meningitidis produced in Bacillus subtilis can give rise to protective immunity. Mol Microbiol 6, 2499-2506.

Peeters, C. C. A. M., Rumke, H. C., Sundermann, L. C., van der Voort, E. M. R., Meulenbelt, J., Schuller, M., Kuipers, A. J., van der Ley, P. \& Poolman, J. T. (1996). Phase I clinical trial with a hexavalent PorA containing meningococcal outer membrane vesicle vaccine. Vaccine 14, 1009-1015.

Perkins, B. A., Jonsdottir, K., Briem, H. \& 16 other authors (1998). Immunogenicity of two efficacious outer membrane proteinbased serogroup B meningococcal vaccines among young adults in Iceland. J Infect Dis 177, 683-691.

Quan, W. D. Y., Dean, G. E., Spears, L., Spears, C. P., Groshen, S., Merritt, J. A. \& Mitchell, M. S. (1997). Active specific immunotherapy of metastatic melanoma with an antiidiotype vaccine: a phase I/II trial of I-Mel-2 plus Saf-M. J Clin Oncol 15, 2103-2110.

Rosenqvist, E., Hoiby, E. A., Wedege, E., Bryn, K., Kolberg, J., Klem, A., Ronnild, E., Bjune, G. \& Nokleby, H. (1995). Human antibody responses to meningococcal outer membrane antigens after three doses of the Norwegian group B meningococcal vaccine. Infect Immun 63, 4642-4652.

Rudbach, J. A., Johnson, D. A. \& Urlich, J. T. (1995). Ribi adjuvants: chemistry, biology and utility in vaccines for human and veterinary medicine. In The Theory and Practical Application of Adjuvants, pp. 287-314. Edited by D. E. S. Stewart-Tull. Chichester: Wiley.

Schultz, N., Oratz, R., Chen, D. L., Zeleniuchjacquotte, A., Abeles, G. \& Bystryn, J. C. (1995). Effect of Detox as an adjuvant for melanoma vaccine. Vaccine 13, 503-508.

Tinsley, C. R. \& Heckels, J. E. (1986). Variation in the expression of pili and outer membrane protein by Neisseria meningitidis during the course of meningococcal infection. J Gen Microbiol 132, 2483-2490.

Tsai, C. M., Frasch, C. E. \& Mocca, L. F. (1981). Five structural classes of major outer-membrane proteins in Neisseria meningitidis. J Bacteriol 146, 69-78.

Van Cott, T. C., Bethke, F. R., Polonis, V. R., Gorny, M. K., Zollapazner, S., Redfield, R. R. \& Birx, D. L. (1994). Dissociation rate of antibody-gp120 binding interactions is predictive of V3mediated neutralization of HIV-1. J Immunol 153, 449-459.

Verma, J. N., Rao, M., Amselem, S., Krzych, U., Alving, C. R., Green, S. J. \& Wassef, N. M. (1992). Adjuvant effects of liposomes containing Lipid A-enhancement of liposomal antigen presentation and recruitment of macrophages. Infect Immun 60, 2438-2444.

van der Voort, E. R., van der Ley, P., van der Biezen, J., George, S., Tunnela, O., van Dijken, H., Kuipers, B. \& Poolman, J. (1996). Specificity of human bactericidal antibodies against PorA P1.7,16 induced with a hexavalent meningococcal outer membrane vesicle vaccine. Infect Immun 64, 2745-2751.

Ward, S. J., Scopes, D. A., Christodoulides, M., Clarke, I. N. \& Heckels, J. E. (1996). Expression of Neisseria meningitidis class 1 porin as a fusion protein in Escherichia coli: the influence of liposomes and adjuvants on the production of a bactericidal immune response. Microb Pathog 21, 499-512.

Wedege, E. \& Froholm, L. O. (1986). Human antibody response to a group B serotype 2a meningococcal vaccine determined by immunoblotting. Infect Immun 51, 571-578.

Wetzler, L. M., Blake, M. S. \& Gotschlich, E. C. (1988). Characterization and specificity of antibodies to protein I of Neisseria gonorrhoeae produced by injection with various protein Iadjuvant preparations. J Exp Med 168, 1883-1897.

White, D. A., Barlow, A. K., Clarke, I. N. \& Heckels, J. E. (1990). Stable expression of meningococcal class 1 protein in an antigenically reactive form in outer membranes of Escherichia coli. Mol Microbiol 4, 769-776.

Received 20 May 1998; revised 22 July 1998; accepted 14 August 1998. 